\title{
Examining the Significance of Gender, Marital Status, Landholding Size and Age of Members on Capacity of Local Level Fish Farmer Organisations
}

\author{
Dalo Njera ${ }^{1}$, Charity Chonde ${ }^{2}$, Daimon Kambewa ${ }^{2}$, Joseph Dzanja ${ }^{2}$, Dennis Kayambazinthu ${ }^{3}$ \\ ${ }^{1}$ Department of Forestry, Faculty of Environmental Sciences, Mzuzu University, Mzuzu City, Malawi \\ ${ }^{2}$ Department of Agricultural Extension and Rural Development, Faculty of Developmental Studies, Lilongwe University of Agriculture and \\ Natural Resources, Lilongwe City, Malawi \\ ${ }^{3}$ Forestry Research Institution of Malawi, Zomba City, Malawi
}

Email address:

dalonjera@yahoo.com (D. Njera), chondecharity@gmail.com (C. Chonde),dkambewa@hotmail.com (D. Kambewa), joseph_dzanja@yahoo.co.uk (J. Dzanja),d_kayamba@hotmail.com (D. Kayambazinthu)

\section{To cite this article:}

Dalo Njera, Charity Chonde, Daimon Kambewa, Joseph Dzanja, Dennis Kayambazinthu. Examining the Significance of Gender, Marital Status, Landholding Size and Age of Members on Capacity of Local Level Fish Farmer Organisations. International Journal of Natural Resource Ecology and Management. Vol. 2, No. 4, 2017, pp. 79-84. doi: 10.11648/j.ijnrem.20170204.12

Received: May 9, 2017; Accepted: May 19, 2017; Published: July 6, 2017

\begin{abstract}
This study ponders on the significance of gender, marital status, landholding size and age of members on capacity of farmer organisations in promoting fish farming at the local level. Purposive sampling method was employed to select five fish farmer organizations. One farmer organisation was selected in Dowa district while four farmer organisations were selected in Mchinji district. All members of the farmer organizations were selected for the study. Both qualitative and quantitative data were collected. Data collection comprised focus group discussions (FGDs), key informant interviews and face to face interviews. Data were analysed using content analysis, critical discourse analysis and descriptive statistics. Results show that gender, marital status, landholding size and age of members have a significant $(p<0.05)$ influence on capacity of farmer organisations to promote fish farming. The study also showed that although institutional theory and social capital theory do not categorically or explicitly point to socioeconomic characteristics of the members as being central in enhancing capacity of the farmer organisations, this study has shown that gender, marital status, landholding size and age of members are critical for the successful performance of fish farmer organisations. It is therefore recommended that these socioeconomic factors be considered for successful establishment and development of vibrant and robust farmer organisations. It is further recommended that a follow-up study with a larger sample and replicated in more local communities should be carried out in order to provide more evidence on the influence of these socioeconomic factors on performance and capacity of fish farmer organisations.
\end{abstract}

Keywords: Socioeconomic Characteristics, Farmer Organisations, Participation, Capacity of Farmer Organisations

\section{Introduction}

Despite the important contribution of fisheries resources to peoples' livelihoods in Malawi, fish catches from water bodies like lakes and rivers have declined [1]. The fish catches declined from an average of 60,000 metric tonnes in the period between 1976 and 1990 to 49,000 metric tones between 1991 and 2003 [2, 3]. Consequently, fisheries resources are no longer available in quantities sufficient to meet the nutritional requirements in Malawi [1]. Per capita consumption of fish in Malawi has therefore declined by more than 100 per cent from $13 \mathrm{~kg}^{-1}$ person $^{-1}$ year in the 1970s to less than $4 \mathrm{~kg}^{-1}$ person $^{-1}$ year in 2005 [3]. The decline is attributed to a number of factors including human population growth which grows at a rate of $2 \%$ per annum, over fishing, use of improper gear and catchment degradation which are putting serious pressures on fishery resources [4].

Considering the decline in the fisheries resources, fish farming or aquaculture is therefore seen as one of the alternative strategies to sustain fish production and supply in Malawi. In Malawi, within the fisheries sector, fish farming has been found to hold the potential for improving productivity of small scale famers and is a major contributor 
to $6 \%$ of agricultural growth [5]. Fish farming has the capacity to increase Malawi's food security through increased food production, household income and improved overall farmland. Commercial aquaculture has the ability to significantly improve the cash economy in areas of the country where fish farming is being practiced, which contributes significantly towards economic growth and job creation in Malawi [2]. It also holds a huge potential to compensate for overburdened fisheries to meet the growing gap between fish supply and demand. In addition, as a technology, aquaculture supplies fish to most upland areas which are not easily accessible to fish from the lakes [1]. Fish farming further accounts for about $2 \%$ of the nation's fish production and contributes between approximately 1 and $17 \%$ of overall household income, depending on the scale of fish farming activities involved [3].

To sustain and promote fish production, the Malawi Government through the Department of Fisheries and Aquaculture provides a number of initiatives aimed at managing and protecting the fish resources. The strategies include sustainable and increased promotion of extension services, strengthening research and enforcement of regulations. These strategies are incorporated in the National Fisheries and Aquaculture Policy of 2001. The policy, through the Department of Fisheries and Aquaculture aims at supporting local communities and the private sector in the development of aquaculture with the overall objective of mobilising local communities to participate in fish farming. The aim of this initiative is to increase and sustain fish production in order to improve fish supply in Malawi. To achieve these initiatives, one of the strategies is the establishment of fish farmer organisations [6]. Fish farmer organisations refer to a group of individual farmers who have voluntarily agreed to cooperate in undertaking fish farming activities within the local communities. This strategy is articulated within the National Fisheries and Aquaculture Policy of 2001. It is therefore the policy that provides the direction on fish farming in Malawi through the involvement of fish farmer organisations.

However, despite the significance of farmer organisations in promoting fish farming in Malawi, there is inadequate substantive evidence to show how member-specific factors influence the capacity of the farmer organisations to enhance fish farming. This study therefore focuses on determining and examining selected member specific characteristics which could affect capacity of the fish farmer organisations. According to Bernard and Spielman [7], the characteristics of members in an organisation also impact on the behaviour of the organisation. The need to understand the characteristics of the individuals in organisations is also stressed by Lobo [8] who reported that the behaviour of members affects performance of farmer organisations in achieving intended goals and objectives. On the same, Stringfellow et al. [9] argues that capacity of farmer organisations depends on the match of the characteristics of individual members to the activities that are to be collectively conducted. Therefore, this study focuses on examining some selected member specific characteristics affecting capacity of the fish farmer organisations. These include gender of members in fish farmer organisations, landholding size of members of fish farmer organisations and age of members of the fish farmer organisations.

\section{Materials and Methods}

This cross-sectional study was carried out in Mchinji and Dowa districts in central Malawi. The sampling frame comprised five fish farmer organizations which operated under Community Action Research Programme (CARP) Fish Project. The farmer organizations comprised a total of 68 fish farmers and all the farmers were selected for this study. Considering the farmers' experiences in fish farming as a result of the previously implemented fish farming projects, it was assumed that members of the fish farmer organizations would be appropriate to provide necessary information for the study. Purposive sampling method was therefore employed to select the five fish farmer organizations and the members of the farmer organizations. Both qualitative and quantitative data were collected in May 2014. The data collection methods comprised focus group discussions (FGDs), key informant interviews and face to face interviews. The FGDs were carried out among members of the farmer groups. Key informant interviews with leaders of the farmer groups and the District Fisheries Officers (DFOs) were further conducted to collect data on insights of the challenges affecting the organizations. Lastly, face to face interviews were conducted in order to understand perceptions of farmers on challenges affecting the farmer organizations. Data were analysed using content analysis, critical discourse analysis and descriptive statistics.

\section{Results and Discussion}

\subsection{Gender Participation and Marital Status of Members in Fish Farmer Organisations}

During the study, of the 68 members of the farmer organisations, $75 \%$ and $25 \%$ were male and female fish farmers, respectively. The gender disparity was observed across all the five fish organisations in Dowa and Mchinji districts with the number of male fish farmers being significantly $\left(\chi^{2}=14.408, \mathrm{df}=4, p=0.006\right)$ higher than that of the female fish farmers. Table 1 presents an overview of gender participation in fish farming activities across the fish farmer organisations.

Table 1. Gender and marital status of members in the fish farmer organisations $(n=68)$.

\begin{tabular}{llll}
\hline \multirow{2}{*}{ Marital status } & Gender \% & \multirow{2}{*}{ Total \% } \\
\cline { 2 - 3 } & Male & Female & \\
\hline Single & $3 \%(2 / 68)$ & $1 \%(1 / 68)$ & $4 \%(3 / 68)$ \\
Married & $63 \%(43 / 68)$ & $18 \%(12 / 68)$ & $81 \%(55 / 68)$ \\
Divorced & 0 & $4 \%(3 / 68)$ & $4 \%(3 / 68)$ \\
Widowed & 0 & $2 \%(1 / 68)$ & $1 \%(1 / 68)$ \\
Polygamous & $9 \%(6 / 68)$ & 0 & $9 \%(6 / 68))$ \\
Total & $75 \%(51 / 68)$ & $25 \%(17 / 68)$ & \\
\hline
\end{tabular}

$\chi^{2}=14.408, \mathrm{df}=4, p=0.006$ 
The findings showed higher male fish farmer domination as compared to women participation in all the fish farmer organisations. However, Chi-square test showed no significant differences in gender participation among female and male farmers across the fish farmer organisations. This implies that in all the fish farmer organisations, the situation was the same in terms of organisational membership with regard to gender where it was found that the membership of men was significantly higher than that of women. This finding depicts the existent trend in gender participation in fish farming in Malawi where aquaculture and capture fisheries sectors are dominated by men $[4,10]$.

Further focus group discussions with members of the fish farmer organisations revealed that the participation of women in decision making within the fish farmer organisations was very low since their male counterparts appeared to dominate. Results showed that that only $10 \%$ of the female members were involved in senior and decision making positions. It was also observed that most of the decision making positions allocated to female members within the fish farmer organisations included the secretarial and treasurer positions. According to key informant interviews with leaders of the farmer groups, these two positions require commitment and faithfulness and hence in most organisations where local communities are involved in collaborative management of their resources, such positions are generally allocated to female members since women are considered to be more committed in record keeping and also faithful in handling institutional assets such as financial resources than their male counterparts.

Furthermore, key informant interviews with office bearers of the farmer organisations and the District Fisheries Officers (DFOs) revealed that the positions of secretary and treasurer call for members of the organisations who have low cases of absenteeism during committee meetings and any other institutional or organisational forums. It was therefore noted that in all the fish farmer groups in Dowa and Mchinji the female members were more committed and also showed low rates of absenteeism during the various institutional gatherings as compared to the male members. Thus, this was the likely reason for their choice as office bearers in more demanding positions within local communities despite these not being part of the decision making positions. In addition, since their proportion as members of the fish farmer groups was lower than that of men, the absenteeism of female members during institutional meetings could easily be noted. This was probably the reason for their low rates of absconding the group meetings. In this regard, although the benefits of organised actions such as the fish farmer organisations are not felt by female farmers, women try their best to be visible in the midst of men by significantly contributing towards success of the organisations [11]. However, while women may comprise $>50 \%$ of the population and while they also form up to $80 \%$ of the farming work as an occupation[12], they have a weak presence in the leadership and decision making positions of the farmer organisations.
Further results showed that the major decision making positions such as the chairperson and vice chairperson were mostly allocated to male members in all the fish farmer organisations in the study areas. Key informant interviews with the DFOs further showed that in terms of decision making powers, the members of the farmer organisations had more confidence in male leaders rather than female ones. While this dominance was attributed to the fact that normally in the rural societies of Malawi women tend not to take part significantly in collaborative activities alongside men, fish farming was also generally regarded as a man's activity and hence the men's dominance in leadership and decision making positions within the farmer organisations. Because of the way they are perceived among the local communities, the study showed that women had limited access and control over agricultural development including fish farming operations. In addition, because fish farming is traditionally under the male domain, programmes including provision of extension services for enhancing fish farming automatically imply that the men should be running the high echelons of fish farming practices.

During the study, focus group discussions with the members of the farmer organisations further revealed that gender roles in the study areas were defined by cultural norms known as mwambo which is a form of ancestral knowledge which outlines what a person's roles, responsibilities and obligations in life will be with the roles passed from men to men and women to fellow women [4]. The traditional culture in Malawi in most cases affects the performance of women in the midst of men in most of development and societal activities. This determines the gender roles between men and women. Furthermore, poverty, traditions, discrimination and systems affect women's status which also negatively affects their membership in fish farming operations. FAO [13] further asserts that in many developing countries, customary beliefs, norms and laws and/or unfavourable regulatory structures reduce women's access to land and water resources which also reduce their chances to become members of the farmer organisations and are rarely consulted in attempts to manage the fisheries resources. Another drawback for women participation as advanced by Agrawal [14] is that the aquaculture sector is often considered a male domain because of the high levels of investment and the adoption of new technologies associated with its development. In addition, although the Malawi National Fisheries Policy desires to promote the participation of women in aquaculture and capture fisheries, it does not specify strategies for this endevour, neither does it provide well articulated provision of extension services approaches to promote women's participation in fish farming in particular. Gender is therefore one of the factors that can influence the success of the fish farmer organisations since men are more likely to take leadership and decision making roles than women.

On marital status, results showed that $80.9 \%(55 / 68)$ of the respondents were married and only $4.4 \%$ (3/68) were single or had never married while another $4.4 \%$ (3/68) and $1.5 \%$ 
$(1 / 68)$ of the members were divorced and widowed, respectively. However, $8.8 \%(6 / 68)$ of the men were married through polygamy where the husband has two or more wives. In both Dowa and Mchinji districts, people practice matrilineal type of marriage where the husband moves to the wife's village. When a valid matrilineal customary marriage has been contracted, the husband is expected to go and live with his wife at his wife's village. This is called chikamwini. Chikamwini is a common feature of matrilineal groups in Malawi. Its original intent seems to have been a way of introducing a dependent male labourer into the wife's family [12].

During focus group discussions, members of the fish farmer groups noted that some men found it a disincentive to undertake fish farming activities as they had a notion that they would lose ownership of the fish ponds in case of divorce or separation. Chikamwini as one of the marriage systems in Malawi therefore acts as a disincentive for some men to engage in fish farming in the two districts. In addition, under the chikamwini marriage system, males despite being heads of households do not have total control of land on which they could carry out fish farming activities. This also reduces the likelihood of men under the chikamwini marriage system to engage in fish farming activities.

\subsection{Landholding Size of Members of Fish Farmer Organisations}

Land holding size included all land available to the fish farmer. Chi-square test showed significant differences $(p<0.05)$ in the number of fish farmers who owned various sizes of land across the farmer organisations in Dowa and Mchinji (Table 2).

Table 2. Landholding size by selected households during the study $(n=68)$.

\begin{tabular}{ll}
\hline Size of land (ha) & Number of respondents \\
\hline$<2.0$ & $40 \%(27 / 68)^{*}$ \\
$2.0-4.0$ & $28 \%(19 / 68)^{*}$ \\
$5.0-7.0$ & $17 \%(11 / 68)^{*}$ \\
$8.0-10.0$ & $10 \%(7 / 68)$ \\
$11.0-13.0$ & $3 \%(2 / 68)$ \\
$\geq 14$ & $3 \%(2 / 68)$ \\
\hline
\end{tabular}

$*$ Significant at $p<0.05$

Results further revealed that most $(40 \% ; 27 / 68)$ of the fish farmers owned less than 2 hectares of land. The mean landholding size per household in the study area was 1.5 hectares. The largest landholding size was 15 hectares per household. Only a few $(3.0 \% ; 2 / 68)$ individuals owned these hectares of land. The smallest landholding size per household was 0.5 hectare. However, the average amount of land owned by the fish farmers in both Dowa and Mchinji was higher than the national average according to the Malawi National Statistical Office (NSO) [15]. This agrees with Garrityet al. [16] who reports that Malawi's agricultural production is characterised by low productivity as well as small landholding size. On average, in Malawi, households cultivate 1.2 hectares of land while per capita landholding size for the rural poor households is as low as 0.23 hectare [17]. In addition, over $40 \%$ of smallholder farmers in Malawi cultivate less than 0.5 hectare of land [18]. This finding is consistent with Bryceson[19] who emphasises that in Malawi, land holdings are small and the majority of smallholder farmers cultivate landholdings that are less than 1 ha. The decrease in land resources and the increase in human population has given way to cultivation of unsuitable and marginal areas.

This study also revealed that $90 \%(61 / 68)$ of the farmers both in Dowa and Mchinji had their fish ponds constructed in swampy sites known as dambo. It was noted that the source of water for most $(90 \%)$ of the ponds was ground water. As a result, most of the ponds were constructed in dambo sites which have higher water table than other sites in order ensure sustainable availability of water in the ponds. It was also observed that within the dambo sites, fish farmers cultivated dimbas where vegetables and other crops such as maize were grown as winter crops through integrated aquaculture agriculture. Therefore, landholding size and ownership and dimba sizes may have a significant influence on the farmers' decision on whether to become a member of the farmer organisation or not. This assertion agrees with Kapandaet al. [20] who found that land holding size had a positive relationship to adoption of fish farming and hence, indirectly influenced membership of the farmer organisations.

\subsection{Age of Members of the Fish Farmer Organisations}

The respondents' ages ranged from 19 to 71 years with a mean age of 39.5 years. Most of the respondents (38\%; 26/68) were between the age range of 41 and 50 years followed by $31-40(22.1 \% ; 15 / 68)$ year's age group (Table 3$)$.

Table 3. Age distribution of fish farmers in farmer organisations $(n=68)$.

\begin{tabular}{llll}
\hline $\begin{array}{l}\text { Age } \\
\text { categories }\end{array}$ & Men & Women & $\begin{array}{l}\text { Total proportion of } \\
\text { fish farmers }\end{array}$ \\
\hline$>21$ & $1 \%(1 / 68)$ & $1 \%(1 / 68)$ & $3 \%(2 / 68)$ \\
$21-30$ & $4 \%(3 / 68)$ & $1 \%(1 / 68)$ & $6 \%(4 / 68)$ \\
$31-40$ & $19 \%(13 / 68)$ & $3 \%(2 / 68)$ & $22 \%(15 / 68)$ \\
$41-50$ & $25 \%(17 / 68)$ & $13 \%(9 / 68)$ & $38 \%(26 / 68)$ \\
$51-60$ & $15 \%(10 / 68)$ & $4 \%(3 / 68)$ & $19 \%(13 / 68)$ \\
$>60$ & $10 \%(7 / 68)$ & $1 \%(1 / 68)$ & $12 \%(8 / 68)$ \\
Total & $75 \%(51 / 68)$ & $25 \%(17 / 68)$ & \\
\hline
\end{tabular}

Results indicate that most $(80.3 \% ; 54 / 68)$ of the fish farmers within the farmer organisations were elderly with ages between 31 years and 60 years with those aged between 41-50 forming a high proportion of the farmers (Table 3). This may be due to the fact that many of those in this age range owned adequate amount of land and hence they have higher likelihood to engage in farming activities including fish farming. Similarly, it was found that the fish farmer organisations were dominated by office bearers whose age range was 41-50 years while the least age group for office bearers ranged between $<21$ and 30 years old. These results are indicative that age could be a determining factor for members of the community in the study area to become members of the fish farmer organisations. This implies that 
older people ( $>40$ years old) were more likely to participate in most of the fish farming as compared to younger people ( $<40$ years old) who could opt for other occupations that may provide immediate returns to investment rather than fish farming.

In addition, the perceived long-term investment in fish farming (six months after stocking fingerings) acts as a disincentive for younger people to undertake fish farming activities at the local level as compared to the older members of the community. This time-lap between fish stocking and harvesting is perceived too long for some farmers to bear before they realize any benefit from their investment. In addition, Chirwa et al. [21] reported that older farmers ( $>40$ years old) in most rural communities have larger farms and households and are probably richer and thus have the extra economic and labour capacity to invest in fish farming, hence their higher proportion in the fish farmer $\mathrm{g}$ as compared to the other age classes of the members.

\section{Conclusion}

The study has revealed that socioeconomic characteristics namely gender, marital status, landholding size and age of members have an important bearing of capacity of the farmer organisations as they influence participation of the members or farmers in the farmer organisations. The study has also shown that although the institutional theory and the social capital theory do not categorically or explicitly point to socioeconomic characteristics of the members as being central in enhancing capacity of the farmer organisations, this study has shown that gender, marital status, landholding size and age of members are critical for the successful performance of the fish farmer organisations. Based on the findings of this study it is recommended that socioeconomic factors be considered for the successful establishment and development of vibrant and robust fish farmer organisations. It is further recommended that a follow-up study with a larger sample and replicated in more local communities should be carried out in order to provide more empirical evidence on the influence of the socioeconomic factors on performance and capacity of the fish farmer organisations.

\section{References}

[1] Kaunda, E., Khando, S., Chitsulo, T., Kapondamgaga, P., Jamu, D., Banda, J., Ng'ong'ola, D., Chirwa, B., Moyo, N. and Maluwa, A. (2010). Enhancing fish production and marketing for food security and rural incomes of small-scale producers in Malawi. Proposal submitted to the RUFORUM CARP programme, Bunda College, Malawi: pp1-3.

[2] Russell A. J. M and Dobson, T. (2009). An adaptive organisational learning framework for resilience in fisheries co-management: Based on analysis of fisheries regimes in Malawi.

[3] Russell, A. J. M., Grötz, P. A., Kriesemer, S. K. and Pemsl, D. E. (2008). Recommendation Domains for Pond Aquaculture. Country Case Study: Development and Status of Freshwater
Aquaculture in Malawi. WorldFish Center Studies and Reviews No. 1869. The WorldFish Center, Penang, Malaysia.

[4] Hara, M. (2007). Dilemmas of Democratic Decentralization in Mangochi District, Malawi: Interest and Mistrust in Fisheries Management. Representation, Equity \& Environment. Working Paper Series. Working Paper 28.

[5] Government of Malawi. (2012). Impact and output indicators for Agriculture, Food Security, Nutrition, Natural resources and Fisheries/Aquaculture projects/programmes in Malawi. A tool to harmonise the monitoring and evaluation system of the Agriculture, Food Security, Nutrition, Natural resources and Fisheries/Aquaculture projects/programmes in Malawi.

[6] Government of Malawi (2001). National Fisheries and Aquaculture Policy. Ministry of Natural Resources and Environmental Affairs. Department of Fisheries. Lilongwe. Malawi.

[7] Bernard, T. and Spielman, D. (2008). Mobilising Rural Institutions for Sustainable Livelihoods and Equitable Development: A case study of Agricultural Marketing Smallholder Cooperatives in Ethiopia. Washington, D. C., USA: International Food Policy Research Institute'.

[8] Lobo, C. (2008). Institutional and organizational analysis for pro-poor change: meeting IFAD's millennium challenge. A source book. The International Fund for Agricultural Development (IFAD). Enabling poor rural people to overcome poverty. Rome, Italy.

[9] Stringfellow, R., Coulter, J., Lucey, T., Mckone, C., \&Hussain, A. (1997). Improving the Access of Smallholder to Agricultural Services in Sub-Saharan Africa: Farmer cooperation and the Role of Donor Community. Natural Resources Perspective 20 ODI. London.

[10] Halfyard, L. C., Matiya, G., Ward, R., Chilera, F. D. Sikawa, $\mathrm{D}$ and Moret, K. (2005). An educational perspective of the constraints to women participation in the aquaculture and fisheries sectors of Malawi.

[11] Penunia, E. A. (2011). The Role of Farmers' Organisations in Empowering and Promoting the Leadership of Rural Women. Accra, Ghana.

[12] Dorward, A., Chirwa, E., Boughton, D., Crawford, E., Jayne, T., Slater, R., Kelly, V. and Tsoka, M. (2008). Towards 'smart' subsidies in agriculture? Lessons from recent experience in Malawi. Overseas Development Institute (ODA), Natural Resource Perspectives 116. United Kingdom.

[13] FAO (2005). The state of food and agriculture. Agricultural Trade and Poverty. Can trade work for the poor? Food and Agriculture Organisation of the United Nations.

[14] Agrawal, A. (2001). Common property institutions and sustainable governance of resources. World Development. Vol 29. No. 10 pp 1649-1672.

[15] NSO, (2008). National Statistical Office (NSO) [Malawi]. The Malawi Population Census. National Statistical Office, Zomba, Malawi.

[16] Garrity, D., Akinnifesi, F., Ajayi, O., Sileshi G. Jeremias, G. Mowo, A., Kalinganire, A., Larwanou, M. and Bayala, J. Evergreen Agriculture: a robust approach to sustainable foodsecurity in Africa. Food Sec. (2010) 2: 197-214. DOI 10.1007/s12571-010-0070-7. 
[17] IFAD, (2009). Sustainability of rural development projects. Best practices and lessons learned. Enabling poor rural people to overcome poverty. Occasional papers. Knowledge for development effectiveness. The eighth in a series of discussion papers produced by the Asia and the Pacific Division.

[18] NSO (2015). National Statistical Office (NSO) [Malawi] and ICF. 2017. 2015-16 Malawi Demographic and Health Survey Key Findings. Zomba, Malawi, and Rockville, Maryland, USA. NSO and ICF.

[19] Bryceson, D. F. (2006). "Ganyu casual labour, famine and HIV/AIDS in rural Malawi: causality and casualty." Journal of Modern African Studies 44(2): 173-202.
[20] Kapanda, K. N., Ng'ong'ola, D. H., Matiya, G. G., Tchale, H., Jamu, D., Kaunda, E. W. K. (2003). Factors affecting adoption of fish farming in Malawi: A case of Mchinji Rural Development Programme. Aqua-Fish Tech. Issue No. 2. Pp 34-38.

[21] Chirwa E, Dorward A, Kachule R, Kumwenda I, Kydd J, Poole N, Poulton C, Stockbridge M (2005). Farmer organizations for market access: Principles for policy and practice.' DFID Report. 